\title{
Oral vitamin A for prevention of mortality and bronchopulmonary dysplasia
}

\author{
Sriparna Basu ${ }^{1,2}$ (D) $\cdot$ Parul Khanna $^{1} \cdot$ Ragini Srivastava $^{3} \cdot$ Ashok Kumar $^{1}$
}

Received: 25 July 2019 / Accepted: 1 August 2019 / Published online: 2 September 2019

(C) Springer-Verlag GmbH Germany, part of Springer Nature 2019

To the Editor,

Dear Sir,

Thank you for showing interest in the article by Basu et al. [1]:

1. The sample size calculation of the study was based on the combined incidence of death and bronchopulmonary dysplasia (BPD) in very low birth weight neonates requiring respiratory support at $24 \mathrm{~h}$ of age in the previous year, which was $64 \%$. We assumed a similar incidence in the placebo group during the study period and expected a relative risk reduction of $20 \%$, i.e., an incidence of $51.2 \%$ [64 - $(20 \%$ of $64=12.8)]$ in the vitamin A group. Using a 1sided test, approximating proportion $1(\mathrm{p} 1)$ and proportion 2 (p2) to be 0.6 and 0.5 for placebo and vitamin A group, respectively (ignoring second decibels), with a confidence level of $95 \%$ and power of $80 \%$, the sample size calculated was 178 in online power/sample size calculator (http:// www.stat.ubc.ca/ rollin/stats/ssize/b2.html). Adding an

This article is a reply to the article https://doi.org/10.1007/s00431-019-03448-y

Communicated by Peter de Winter

Sriparna Basu

drsriparnabasu@ rediffmail.com

Parul Khanna

khanna.paru190@gmail.com

Ragini Srivastava

raginibiochembhu@gmail.com

Ashok Kumar

ashokkumar_bhu@hotmail.com

1 Neonatal Unit, Department of Pediatrics, Institute of Medical Sciences, Banaras Hindu University, Varanasi, India

2 Department of Neonatology, All India Institute of Medical Sciences, Rishikesh, India

3 Department of Biochemistry, Institute of Medical Sciences, Banaras Hindu University, Varanasi, India attrition of $10 \%$, total sample size calculated was 196 (as mentioned in the study).

It is difficult to explain why the primary outcome (combined incidence of mortality or BPD) during the study period was less compared with the previous year. There were no significant changes in neonatal care practices, ventilatory strategies, or any systematic quality improvement initiative in the unit during the study period.

2. BPD was defined as an oxygen requirement for 28 days. Only 2 infants in the vitamin A group and 9 in the placebo group needed oxygen for 28 days. In majority of neonates, oxygen was used for a short period, thus accounting for an overall shorter duration of oxygen requirement in the study cohort.

3. The osmolality of the aqueous oral vitamin A solution was not measured, as we did not have the facility in our hospital. It is difficult to say whether there was any association of necrotising enterocolitis with vitamin A supplementation due to small number of the incidence. Studies with a large sample size are needed to confirm or refute this observation.

Authors' contributions Prof. Sriparna Basu and Prof. Ashok Kumar drafted the initial manuscript. Dr. Parul Khanna and Dr. Ragini Srivastava reviewed and revised the manuscript. All authors approved the final manuscript as submitted and agree to the content.

\section{Compliance with ethical standards}

Conflict of interest The authors declare that they have no conflict of interest.

\section{Reference}

1. Basu S, Khanna P, Srivastava R, Kumar A (2019) Oral vitamin A supplementation in very low birth weight neonates: a randomized controlled trial. Eur J Pediatr 178:1255-1265

Publisher's note Springer Nature remains neutral with regard to jurisdictional claims in published maps and institutional affiliations. 